\title{
From the Editor of Sexuality and Disability: A New Year of Opportunity for Collaboration to Work Together on Issues Related to Sexuality and Disability
}

\author{
Sigmund Hough ${ }^{1}$
}

Published online: 1 February 2018

(C) Springer Science+Business Media, LLC, part of Springer Nature 2018

The journal of Sexuality and Disability remains a professional home and foundation for many, and a place of professional rejuvenation and exploration for still more. If you are new to the journal, we give to you a "BIG WELCOME" to participate as a reader, author, academician, clinician, educator, service provider, researcher, advocate, and individual or individuals seeking information. Over decades of contribution to the literature on sexuality and disability, we have been a part of the growth and understanding. Now most importantly, we continue to be a part of change in how we look and examine the topic, the need, and the response in terms of best practice- evidence based approaches. With the intelligence, experience, motivation and supportive commitment from our authors, readership, peer reviewers and editorial board, and resources with guidance from the Springer Staff, our journal's mission continues to be strong and meaningful. This international team effort continues as a strength in the field of sexuality and disability.

Sexuality and Disability continues to provide original impact articles addressing the mental health and medical aspects of sexuality in relation to rehabilitation, hospital, academic and community settings, publishing up-to-date articles, case studies, clinical practice reports, reviews, featured articles, historical articles, special grand rounds topics, brief research reports and survey data reports. Value benefit is provided to authors through worldwide electronic exposure and professional access, while readership gains from scholarly contributions to advance the field through research, best-practice and educational articles. The refined lens of individual contributions from the local and international community continues to deliver a wealth of information on the topic of sexuality and disability for the reader. Thank you for joining our professional community.

As we begin 2018, we give special appreciation and recognition to the current and past Editorial Board Members, and Reviewers for their specific dedication and expertise in the

Sigmund Hough

Sigmund_Hough@hms.harvard.edu

1 Beverly, MA 01915-6144, USA 
field of sexuality and disability. Similarly, we are grateful to Springer and Staff for providing a consistent high powered respectful and accessible academic forum. We also appreciate the commitment and efforts in sharing from an international community that includes authorship and readership. And so we begin a New Year! 